\title{
Does office-based flexible cystoscopy provide better pain perception than rigid cystoscopy: a systematic review and meta- analysis
}

\author{
Dechao Feng $^{1 \#}$, Guo Chen ${ }^{2 \#}$, Yubo Yang $^{1 \wedge}$, Wuran $\mathrm{Wei}^{1 \wedge}, \mathrm{Xin}_{\mathrm{Wei}^{1} \wedge}$ \\ ${ }^{1}$ Department of Urology, Institute of Urology, West China Hospital, Sichuan University, Chengdu, China; ${ }^{2}$ Department of Urology, West China \\ School of Public Health and West China Fourth Hospital, Sichuan University, Chengdu, China \\ Contributions: (I) Conception and design: D Feng; (II) Administrative support: W Wei, X Wei; (III) Provision of study materials or patients: D Feng, \\ G Chen; (IV) Collection and assembly of data: D Feng, Y Yang; (V) Data analysis and interpretation: D Feng, G Chen; (VI) Manuscript writing: All \\ authors; (VII) Final approval of manuscript: All authors. \\ \#These authors contributed equally to this work. \\ Correspondence to: Xin Wei, PhD. Department of Urology, Institute of Urology, West China Hospital, Sichuan University, Guoxue Xiang \#37, \\ Chengdu 610041, China. Email: xweiwch@126.com.
}

\begin{abstract}
Background: The aim of our study is to determine whether flexible cystoscopy (FC) leads to less pain perception than rigid cystoscopy $(\mathrm{RC})$.

Methods: Eligible studies were identified through three common databases, including PubMed, the Cochrane Library and Embase. We systematically reviewed studies comparing FC to RC, and extracted data from randomized trials from December 1, 1984 to January 12, 2021, with no language restrictions. Methodological rigor, and risk of bias were evaluated by two independent reviewers using Cochrane Collaboration's tools. The analysis was completed via STATA version 14.2.

Results: We initially identified 463 studies, and four articles met the criteria for inclusion. Overall, we did not observe a significant difference between $\mathrm{FC}$ and $\mathrm{RC}$ regarding pain perception [standard mean difference (SMD): $-1.19 ; 95 \% \mathrm{CI}:-2.69$ to 0.32$]$, and there was significant heterogeneity among studies $\left(\mathrm{I}^{2}=97.6 \%\right.$, $\mathrm{P}<0.001$ ). This was consistent with the results stratified by gender (male patients, SMD: $-0.96,95 \% \mathrm{CI}$ : -2.50 to 0.59 ; female patients, SMD: -1.42 ; $95 \%$ CI: -4.49 to 1.64 ).

Conclusions: Our study revealed that RC is a tolerable procedure, and FC may not be more comfortable than RC. However, further larger well-designed trials are warranted to demonstrate our findings, and explore whether FC is more beneficial to patient sexual function, anxiety, quality of life, and lower urinary tract symptoms than RC.
\end{abstract}

Keywords: Flexible cystoscopy (FC); rigid cystoscopy (RC); pain perception

Submitted Feb 04, 2021. Accepted for publication Apr 28, 2021.

doi: $10.21037 /$ apm-21-316

View this article at: http://dx.doi.org/10.21037/apm-21-316

\section{Introduction}

It is universally acknowledged that cystoscopy is the one of the most common outpatient procedures in urology clinical practice. Patients are usually recommended to undergo cystoscopy when they have hematuria, regular surveillance or under suspicion of bladder cancer after transurethral

\footnotetext{
^ ORCID: Dechao Feng, 0000-0002-8267-9920; Yubo Yang, ORCID: 0000-0002-0189-3256; Wuran Wei, ORCID: 0000-0002-2133-6043; Xin Wei, ORCID: 0000-0001-9363-0455.
} 
resection of non-muscle-invasive bladder tumor, recurrent lower urinary tract symptoms, and intractable urinary tract infections $(1,2)$. However, many patients are afraid of this clinical examination due to pain perception (2). Currently, researchers have conducted many trials to seek potentially adjuvant therapy to alleviate patient pain during cystoscopy, especially for male patients. The proposed nonpharmacological methods included increasing irrigation pressure (3-5), delaying the instillation time of topical anesthetics in the urethra (6-8), allowing patients to watch the procedure process (9-11), listening to music $(12,13)$, hand-holding (14), urinating during FC (15), and virtual reality distraction (16). All these interventions are practical, inexpensive, and harmless.

In many countries flexible cystoscopy (FC) is the preferred out-patient method, however, rigid cystoscopy (RC) is indispensable ascribed to its better visual performance, lower costs and easier operation compared to $\mathrm{FC}$. Whether FC provides better pain perception is still a controversial issue, and thereby we conduct this meta-analysis to explore the effect of different cystoscopy on pain perception in patients undergoing cystoscopy in the outpatient clinic. We present the following article in accordance with the PRISMA reporting checklist (available at http://dx.doi.org/10.21037/apm-21-316).

\section{Methods}

\section{Search strategy}

A systematic review and literature search were conducted according to the PRISMA guidelines (17). Eligible studies were identified through three common databases including PubMed, the Cochrane Library and Embase from December 1, 1984 to January 12, 2021 regardless of language, and the related reference lists were also retrieved manually. The used keywords or mesh terms in this study were "flexible", "rigid", and "cystoscopy". Details of search strategy on PubMed were as follows: ((flexible [Title/ Abstract]) AND ((()((()(((Cystoscopy [Title/Abstract]) OR (Cystoscopies [Title/Abstract])) OR (Cystoscopic Surgical Procedures [Title/Abstract])) OR (Cystoscopic Surgical Procedure [Title/Abstract])) OR (Procedure, Cystoscopic Surgical [Title/Abstract])) OR (Procedures, Cystoscopic Surgical [Title/Abstract])) OR (Surgical Procedure, Cystoscopic [Title/Abstract])) OR (Surgery, Cystoscopic [Title/Abstract])) OR (Surgical Procedures, Cystoscopic [Title/Abstract])) OR (Cystoscopic Surgery [Title/
Abstract])) OR (Cystoscopic Surgeries [Title/Abstract])) OR (Surgeries, Cystoscopic [Title/Abstract]))) AND (rigid [Title/Abstract]).

\section{Study selection}

We used the PICOS method to identify eligible patients. Patients $(\mathrm{P})$ : patients who could communicate with operators normally; intervention (I): patients in experimental group underwent $\mathrm{FC}$; comparison $(\mathrm{C})$ : comparing $\mathrm{FC}$ to $\mathrm{RC}$; outcomes $(\mathrm{O})$ : pain perception was measured by visual analogue pain scale (VAS); study design (S): randomized controlled trials; exclusion criteria included the following items: (I) no systemic sedation or analgesia before cystoscopy; (II) current urinary infection; (III) presence of current pain in the pelvic region (e.g., bladder pain syndrome or interstitial cystitis); (IV) pregnancy; (V) prior urethral surgery; (VI) cystoscopy with other interventions; (VII) data not available; (VIII) meeting abstracts. Figure 1 showed the flowchart of study selection process in this study.

\section{Data extraction and quality assessment}

We firstly imported the retrieved publications into the Endnote. Two independent authors screened the search results based on the title, abstract, and final full text. Discrepancies are settled through discussion. Two independent reviewers used the preformulated tables to extract data. The following data were extracted: the first author's name, year of publication, country, period, age, sample size, local anesthesia, selection criteria, pain perception, and cystoscopy type.

Two independent authors evaluated the methodological quality of the studies according to the Cochrane Collaboration's Risk of Bias (RoB) tool in Review Manager software. This tool primarily evaluates 7 domains: random sequence generation (selection bias); allocation concealment (selection bias); blinding of participants and personnel (performance bias); blinding of outcome assessment (detection bias); incomplete outcome data (attrition bias); selective reporting (reporting bias); other bias (such as funding sources). Moreover, two reviewers independently rated the level of evidence of the included articles through the Oxford Centre for Evidence-Based Medicine criteria (18); This scale graded studies from strongest (level 1) to weakest (level 5) strength of evidence according to study design and data quality. 


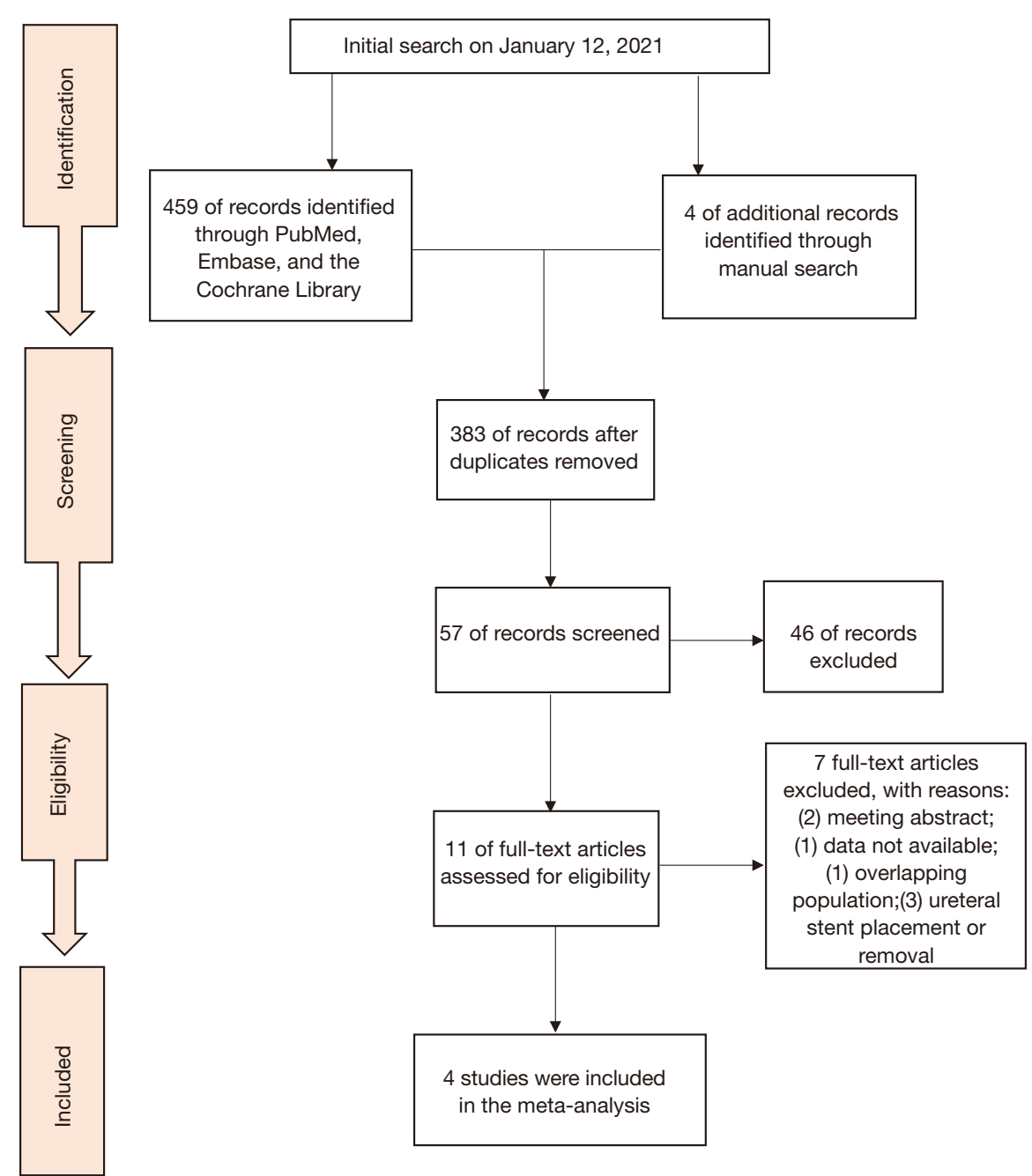

Figure 1 The flowchart of study selection in this study.

Figure 2 showed the RoB summary of the four studies (5-8). Overall, included studies had a low risk of selection bias, attrition bias and reporting bias. However, the risk of performance bias was high. The risk of detection bias was unclear due to absence of related description.

\section{Statistical analysis}

Continuous variables presented as means and corresponding standard deviations (SD) were pooled for mean difference (MD) or standard MD (SMD). The fixed effects model was used unless there exists heterogeneity $(\mathrm{P}<0.1)$, and significance was set at $\mathrm{P}<0.05$. Additionally, we performed a subgroup analysis based on gender. This meta-analysis was completed by STATA version 14.2.

\section{Results}

\section{Search results}

We initially identified 463 studies, and four articles (19-22) met the criteria for inclusion. Two studies $(19,20)$ compared FC to RC in 141 male patients, and the other two studies $(21,22)$ investigated the two cystoscopy methods in 274 female patients. The participants came from the Netherlands, USA, Poland, and Turkey. Table 1 presented the main characteristics of included studies in this metaanalysis.

\section{Meta-analysis results}

Overall, we did not observe a significant difference between 


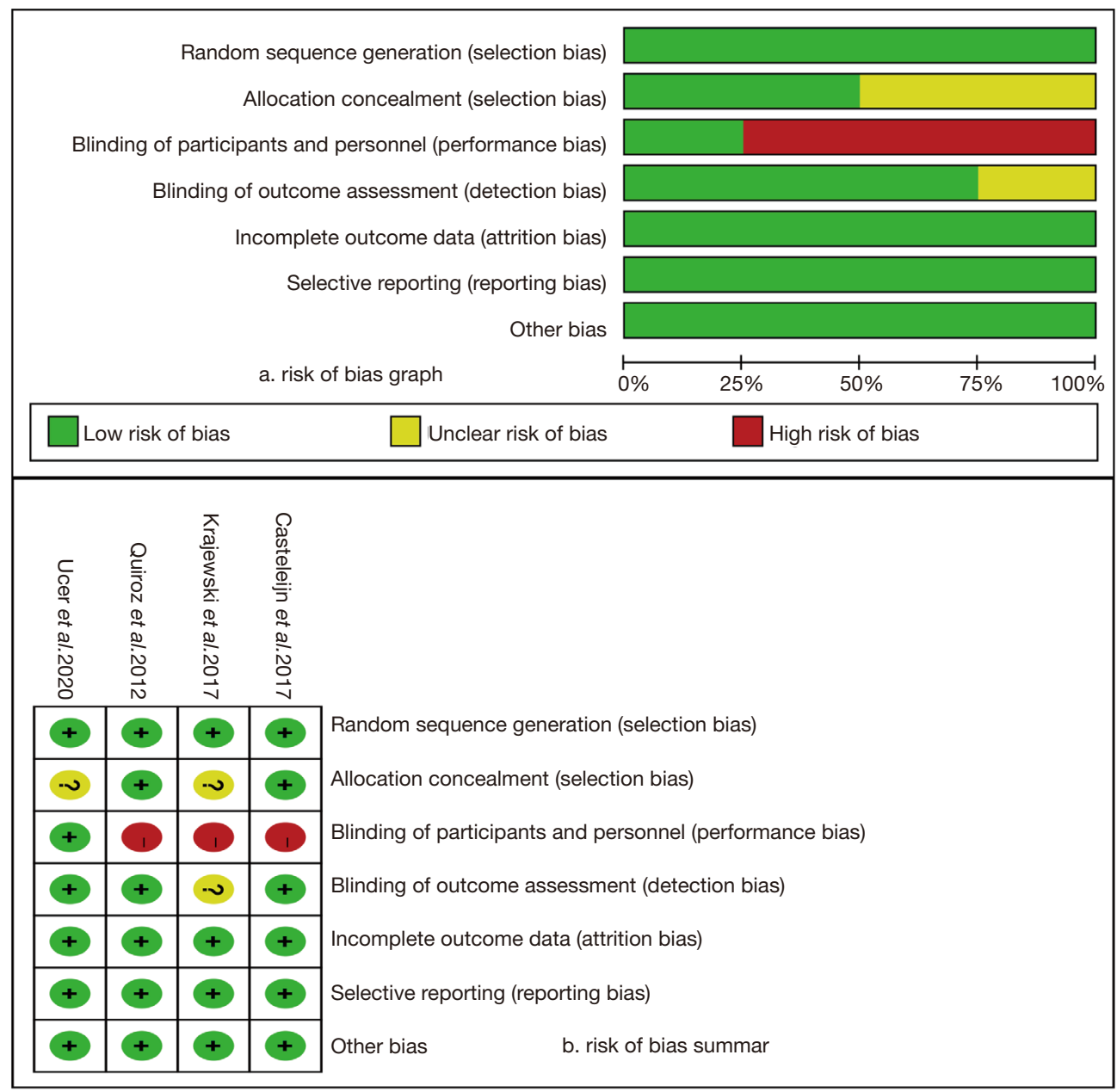

Figure 2 The methodological quality of studies included in this study.

FC and RC regarding pain perception (SMD: $-1.19 ; 95 \%$ CI: -2.69 to 0.32 ; Figure 3) with great between-study heterogeneity $\left(\mathrm{I}^{2}=97.6 \%, \mathrm{P}<0.001\right)$. This was in keeping with the results stratified by gender (male patients: SMD: $-0.96,95 \%$ CI: -2.50 to 0.59 ; female patients: SMD: -1.42 ; 95\% CI: -4.49 to 1.64 ; Figure 3).

\section{Discussion}

Cystoscopy is commonly conducted with $2 \%$ lidocaine gel administrating intraurethrally for several minutes to reduce pain before procedure in many urologic institutes $(23,24)$. Nonetheless, it is difficult to achieve optimal analgesic effect due to procedural invasiveness. In 1973, Tsuchida Seigi and Sugawara Hiroatsu firstly introduced FC, which was potentially less painful than RC (25). Subsequently, many institutions routinely performed $\mathrm{FC}$ in their urology outpatient, and some studies believed that FC was more comfortable than RC $(20,26)$. The EAU guidelines reported that FC led to better compliance than RC under topical anesthetics instillation in the urethra, especially in male patients due to prostate, tight sphincter, and longer urethra (27). In the present study, no significant pain relief was identified in patients undergoing FC when compared to RC.

The friction between cystoscope and urethral mucosa leads to bleeding and pain perception. Several studies believed that the location of most painful part in FC was the membranous urethra of external sphincter $(12,28)$. For the past decades, many investigators have proposed several 


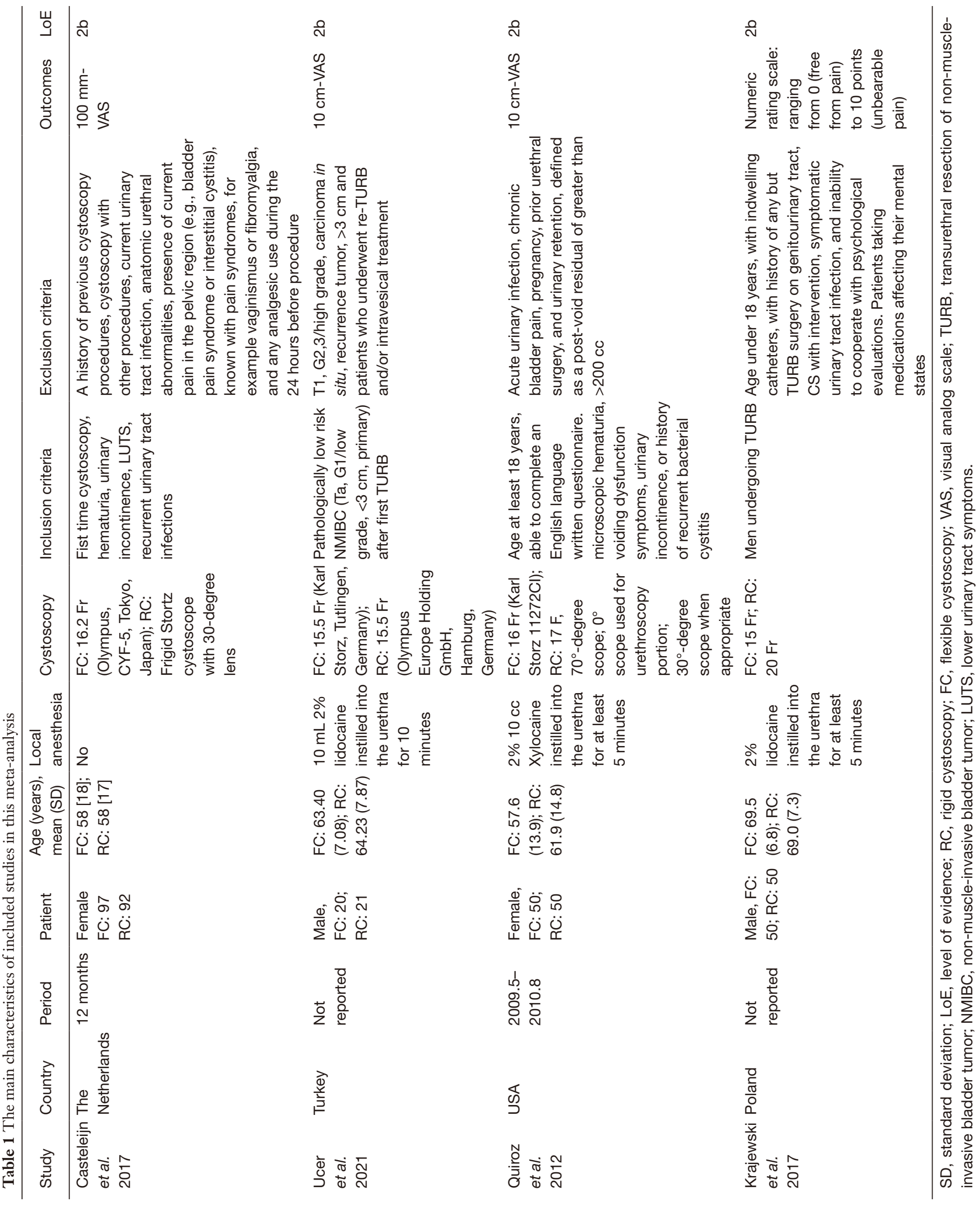




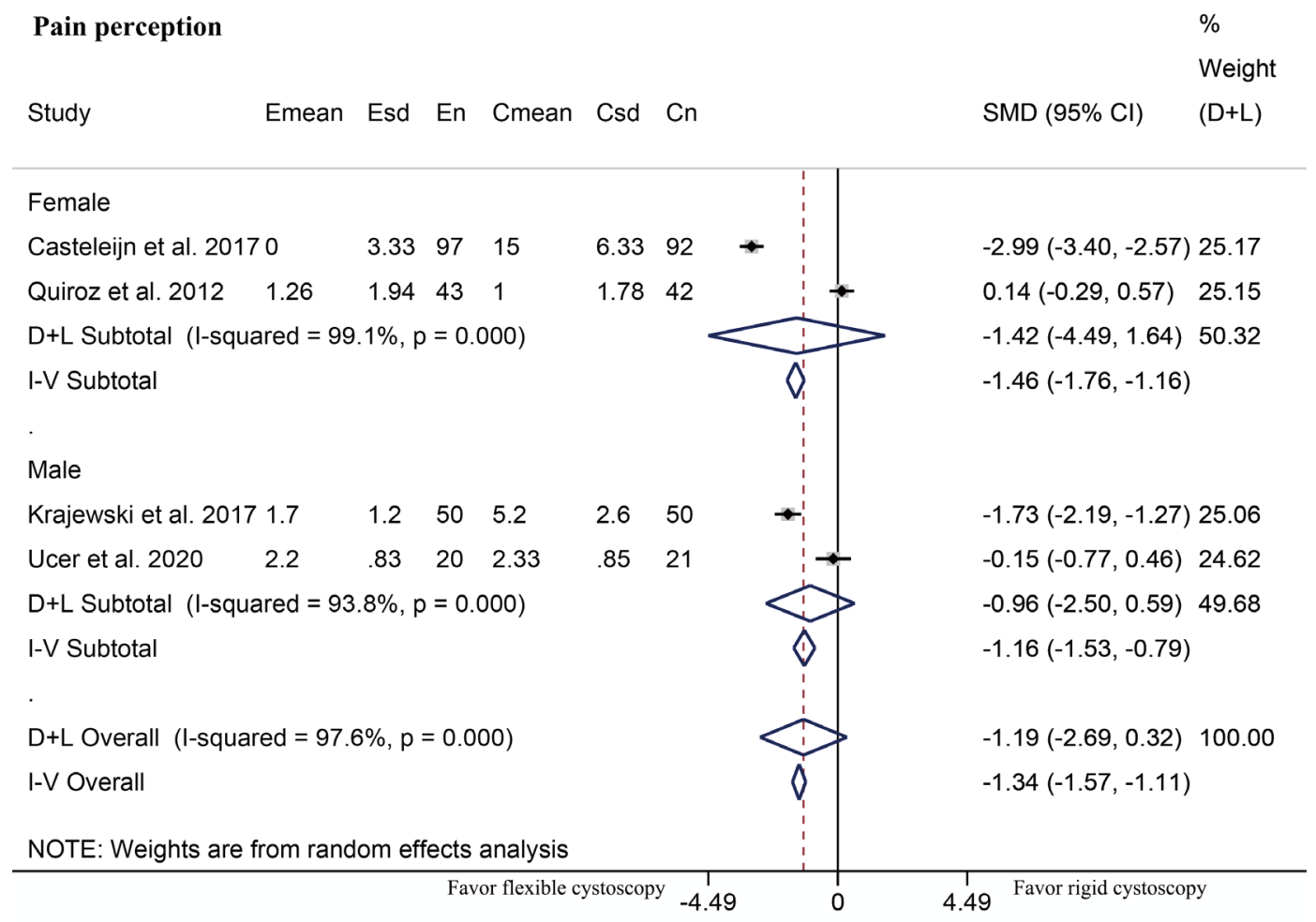

Figure 3 The pooled results of the evaluated outcomes in this study.

methods to relieve patient discomfort, such as parenteral agents (29), inhalational agents (30), watching video (9,31), Bag Squeeze (4,5), and listening to music (12,13,32-35). Besides, FC contribute to less pain than RC for patients with obvious bladder neck elevation according to our clinical experience, because RC is more likely to touch the urethral mucosa for these patients. Perhaps FC is more suitable for selective male patients, such as patients with obvious bladder neck elevation. We still need large clinical trials to confirm this finding.

It is undeniable that out study has following limitations. Firstly, the limited number of studies, sample size, different size of cystoscopy, and ethnic differences in penis prevented us from making a definite conclusion. Secondly, we were unable to evaluate the effect of $\mathrm{FC}$ and $\mathrm{RC}$ on discomfort in the Asian patients due to smaller penis size and diameter in the Asian countries than those in the western and African countries in most cases. Thirdly, we did not have the ability to further assess the influence of different cystoscopy methods on patient sexual function, anxiety, quality of life, and lower urinary tract symptoms. Furthermore, we were also unable to assess the impact of the number of procedures on pain perception due to insufficient data.

\section{Conclusions}

Our study revealed that RC is a tolerable procedure, and FC may not be more comfortable than RC. However, further larger well-designed trials are warranted to demonstrate our findings, and explore whether FC is more beneficial to patient sexual function, anxiety, quality of life, and lower urinary tract symptoms than RC.

\section{Acknowledgments}

We thank Prof. Gong Juan from the College of Foreign Languages, Sichuan University for her contribution of editing the language of this study.

Funding: This work was supported by Department of Science and Technology of Sichuan Province (2020YFH0099) and Special fund for science and technology cooperation between Sichuan University and 
Panzhihua City (No.2018CDPZH-29).

\section{Footnote}

Reporting Checklist: The authors have completed the PRISMA reporting checklist. Available at http://dx.doi. org/10.21037/apm-21-316

Conflicts of Interest: All authors have completed the ICMJE uniform disclosure form (available at http://dx.doi. org/10.21037/apm-21-316). The authors have no conflicts of interest to declare.

Ethical Statement: The authors are accountable for all aspects of the work in ensuring that questions related to the accuracy or integrity of any part of the work are appropriately investigated and resolved.

Open Access Statement: This is an Open Access article distributed in accordance with the Creative Commons Attribution-NonCommercial-NoDerivs 4.0 International License (CC BY-NC-ND 4.0), which permits the noncommercial replication and distribution of the article with the strict proviso that no changes or edits are made and the original work is properly cited (including links to both the formal publication through the relevant DOI and the license). See: https://creativecommons.org/licenses/by-nc-nd/4.0/.

\section{References}

1. Burke DM, Shackley DC, O'Reilly PH. The communitybased morbidity of flexible cystoscopy. BJU Int 2002;89:347-9.

2. Greenstein A, Greenstein I, Senderovich S, et al. Is diagnostic cystoscopy painful? Analysis of 1,320 consecutive procedures. Int Braz J Urol 2014;40:533-8.

3. Zhang ZS, Wang XL, Zeng SX, et al. Pressure Makes Pleasure: A Preliminary Study of Increasing Irrigation Pressure of Flexible Cystoscopy Improves Male Patient Comfort by an Easy Way. J Endourol 2015;29:1361-5.

4. Berajoui MB, Aditya I, Herrera-Caceres J, et al. A Prospective Randomized Controlled Trial of Irrigation "Bag Squeeze" to Manage Pain for Patients Undergoing Flexible Cystoscopy. J Urol 2020;204:1012-8.

5. Gunendran T, Briggs RH, Wemyss-Holden GD, et al. Does increasing hydrostatic pressure ("bag squeeze") during flexible cystoscopy improve patient comfort: a randomized, controlled study. Urology 2008;72:255-8.
6. Herr HW, Schneider M. Outpatient flexible cystoscopy in men: a randomized study of patient tolerance. J Urol 2001;165:1971-2.

7. Losco G, Antoniou S, Mark S. Male flexible cystoscopy: does waiting after insertion of topical anaesthetic lubricant improve patient comfort? BJU Int 2011;108 Suppl 2:42-4.

8. Panach-Navarrete J, Martínez-Jabaloyas JM. Is a retention time after the instillation of anesthetic lubricant necessary when performing male flexible cystoscopy? J Endourol 2015;29:223-5.

9. Patel AR, Jones JS, Angie S, et al. Office based flexible cystoscopy may be less painful for men allowed to view the procedure. J Urol 2007;177:1843-5.

10. Cornel EB, Oosterwijk E, Kiemeney LA. The effect on pain experienced by male patients of watching their officebased flexible cystoscopy. BJU Int 2008;102:1445-6.

11. Zhang ZS, Tang L, Wang XL, et al. Seeing is believing: a randomized controlled study from China of real-time visualization of flexible cystoscopy to improve male patient comfort. J Endourol 2011;25:1343-6.

12. Zhang ZS, Wang XL, Xu CL, et al. Music reduces panic: an initial study of listening to preferred music improves male patient discomfort and anxiety during flexible cystoscopy. J Endourol 2014;28:739-44.

13. Ölçücü MT, Yılmaz K, Karamık K, et al. Effects of Listening to Binaural Beats on Anxiety Levels and Pain Scores in Male Patients Undergoing Cystoscopy and Ureteral Stent Removal: A Randomized PlaceboControlled Trial. J Endourol 2021;35:54-61.

14. Kwon WA, Lee JW, Seo HK, et al. Hand-Holding during Cystoscopy Decreases Patient Anxiety, Pain, and Dissatisfaction: A Pilot Randomized Controlled Trial. Urol Int 2018;100:222-7.

15. Xie $Y$, Wang $W$, Yan W, et al. Efficacy of urination in alleviating man's urethral pain associated with flexible cystoscopy: a single-center randomized trial. BMC Urol 2020;20:2.

16. Walker MR, Kallingal GJ, Musser JE, et al. Treatment efficacy of virtual reality distraction in the reduction of pain and anxiety during cystoscopy. Mil Med 2014;179:891-6.

17. Moher D, Liberati A, Tetzlaff J, et al. Preferred reporting items for systematic reviews and meta-analyses: the PRISMA statement. PLoS Med 2009;6:e1000097.

18. Centre for Evidence-Based Medicine. Oxford Centre for evidence-based medicine: levels of evidence, 2009. Available online: http://www.cebm. net/oxfordcentreevidence-based-medicine-levels- 
evidencemarch-2009/

19. Ucer O, Temeltas G, Gumus B, et al. Comparison of pain, quality of life, lower urinary tract symptoms and sexual function between flexible and rigid cystoscopy in followup male patients with non muscle invasive bladder cancer: A randomized controlled cross section single blind study. Int J Clin Pract 2021;75:e13853.

20. Krajewski W, Kościelska-Kasprzak K, Rymaszewska $\mathrm{J}$, et al. How different cystoscopy methods influence patient sexual satisfaction, anxiety, and depression levels: a randomized prospective trial. Qual Life Res 2017;26:625-34.

21. Quiroz LH, Shobeiri SA, Nihira MA, et al. Randomized trial comparing office flexible to rigid cystoscopy in women. Int Urogynecol J 2012;23:1625-30.

22. Casteleijn NF, Vriesema JL, Stomps SP, et al. The effect of office based flexible and rigid cystoscopy on pain experience in female patients. Investig Clin Urol 2017;58:48-53.

23. Raskolnikov D, Brown B, Holt SK, et al. Reduction of Pain during Flexible Cystoscopy: A Systematic Review and Meta-Analysis. J Urol 2019;202:1136-42.

24. Aaronson DS, Walsh TJ, Smith JF, et al. Meta-analysis: does lidocaine gel before flexible cystoscopy provide pain relief? BJU Int 2009;104:506-9; discussion 509-10.

25. Tsuchida S, Sugawara H. A new flexible fibercystoscope for visualization of the bladder neck. J Urol 1973;109:830-1.

26. Seklehner S, Remzi M, Fajkovic H, et al. Prospective multi-institutional study analyzing pain perception of flexible and rigid cystoscopy in men. Urology 2015;85:737-41.

27. Babjuk M, Böhle A, Burger M, et al. EAU Guidelines on Non-Muscle-invasive Urothelial Carcinoma of the

Cite this article as: Feng D, Chen G, Yang Y, Wei W, Wei $\mathrm{X}$. Does office-based flexible cystoscopy provide better pain perception than rigid cystoscopy: a systematic review and metaanalysis. Ann Palliat Med 2021;10(6):6228-6235. doi: 10.21037/ apm-21-316
Bladder: Update 2016. Eur Urol 2017;71:447-61.

28. Taghizadeh AK, El Madani A, Gard PR, et al. When does it hurt? Pain during flexible cystoscopy in men. Urol Int 2006;76:301-3.

29. Song YS, Song ES, Kim KJ, et al. Midazolam anesthesia during rigid and flexible cystoscopy. Urol Res 2007;35:139-42.

30. Calleary JG, Masood J, Van-Mallaerts R, et al. Nitrous oxide inhalation to improve patient acceptance and reduce procedure related pain of flexible cystoscopy for men younger than 55 years. J Urol 2007;178:184-8.

31. Gezginci E, Bedir S, Ozcan C, et al. Does Watching a Relaxing Video During Cystoscopy Affect Pain and Anxiety Levels of Female Patients? A Randomized Controlled Trial. Pain Manag Nurs 2021;22:214-9.

32. Raheem OA, Mirheydar HS, Lee HJ, et al. Does Listening to Music During Office-Based Flexible Cystoscopy Decrease Anxiety in Patients: A Prospective Randomized Trial. J Endourol 2015;29:791-6.

33. Yeo JK, Cho DY, Oh MM, et al. Listening to music during cystoscopy decreases anxiety, pain, and dissatisfaction in patients: a pilot randomized controlled trial. J Endourol 2013;27:459-62.

34. Gezginci E, Iyigun E, Kibar Y, et al. Three Distraction Methods for Pain Reduction During Cystoscopy: A Randomized Controlled Trial Evaluating the Effects on Pain, Anxiety, and Satisfaction. J Endourol 2018;32:1078-84.

35. Gupta S, Das SK, Jana D, et al. Distraction during cystoscopy to reduce pain and increase satisfaction: Randomized control study between real-time visualization versus listening to music versus combined music and realtime visualization. Urol Ann 2019;11:33-8. 